\title{
Temas de Interesse e Artigos de Mais Procura Publicados no Último Ano
}

\author{
Áurea J. Chaves
}

$\mathbf{N}$ o último ano, alguns temas discutidos na Revista Brasileira de Cardiologia Invasiva (RBCI), como o implante percutâneo de válvula aórtica (TAVI), os stents coronários de última geração, o uso de estratégias adjuntas para guiar intervenções coronárias percutâneas (ICP), como o ultrassom intracoronário ou o fluxo fracionado de reserva miocárdica (FFR), e o tratamento das cardiopatias congênitas, atraíram grande interesse dos leitores. A atual edição traz artigos que exploram novos aspectos desses tópicos.

Ribeiro et al., do Quebec Heart \& Lung Institute, Laval University (Quebec, Canadá), por meio de uma revisão sistemática, apresentam as características clínicas, o manejo e os desfechos clínicos de pacientes com obstrução coronária pós-TAVI valve-in-valve. Trata-se de complicação rara, mas potencialmente fatal, e o artigo identifica fatores associados à obstrução coronária que devem ser observados antes do procedimento, como a altura do óstio do tronco de coronária esquerda e o diâmetro médio da raiz aórtica, obtidos pela tomografia computadorizada, além do tipo de bioprótese cirúrgica previamente implantada. Os autores descrevem o quadro clínico (hipotensão persistente, associada ou não às alterações do segmento ST) e os resultados pouco satisfatórios da ICP nesse cenário. Adicionalmente, Candiello et al., do Instituto Cardiovascular de Buenos Aires (Buenos Aires, Argentina), relatam a experiência de 51 casos de TAVI tratados com a prótese CoreValve ${ }^{\circledR}$ e sua evolução pós-procedimento. Gradientes transvalvares, classe funcional e mortalidade estão detalhadamente expostos nas fases pré e pós-procedimento, e aos 30 dias, 6 meses e 1 ano.

Autores do Instituto Dante Pazzanese de Cardiologia (São Paulo, SP) trazem, em seus artigos originais, aspectos relacionados ao desempenho dos suportes vasculares bioabsorvíveis, da primeira experiência clínica brasileira com esse novo dispositivo. Borghi Jr. et al. analisam a retração aguda do vaso imediatamente após o procedimento, fenômeno ligado à força radial dos stents e motivo de preocupação com os primeiros protótipos poliméricos. Concomitantemente, Veloso e Silva et al. abordam as modificações da angulação do vaso, ao avaliarem as alterações que tais próteses trazem ao segmento coronário tratado, quando comparadas às plataformas metálicas dos stents farmacológicos de segunda geração. A retificação de um segmento curvo de um vaso, após o implante de stent, pode modificar a dinâmica do fluxo coronário e alterar a distribuição da hiperplasia intimal intrastent, durante a fase de cicatrização do mesmo.

No cenário dos métodos adjuntos, Quizhpe et al., do Hospital José Carrasco Arteaga (Cuenca, Equador), mostram sua experiência no tratamento de lesões de tronco de coronária esquerda com a utilização do ultrassom intracoronário e/ou FFR para guiar a maioria dos procedimentos. Trata-se de descrição extremamente detalhada das intervenções, nas quais estão presentes não só as avaliações do EuroScore, do escore Syntax e da classificação de Medina, como o tipo de técnica utilizada, as medidas da angiografia coronária quantitativa e os resultados clínicos de longo prazo. Por outro lado, Brito et al., da Clínica Santa Helena (Cabo Frio, RJ), um dos grupos pioneiros no Brasil na utilização do FFR, descrevem as variáveis preditoras de FFR pósprocedimento $<0,90$ em pacientes submetidos à ICP. Sabe-se que esses pacientes apresentam índice de eventos cardíacos adversos maiores em 6 meses três vezes maior que aqueles com FFR pós-procedimento $\geq 0,90$.

Dentro da temática das cardiopatias congênitas, Haddad et al., do Hospital das Clínicas da Faculdade de Medicina de Ribeirão Preto da Universidade de São Paulo (Ribeirão Preto, SP), trazem sua experiência inicial com nova prótese de duplo disco para o tratamento percutâneo da comunicação interatrial do tipo ostium secundum. Trata-se de uma das primeiras publicações dos resultados dessa prótese na literatura mundial. Complementa o artigo o editorial correspondente de Francisco Chamié, do Hospital Federal dos Servidores do Estado (Rio de Janeiro, RJ), que, com sua maestria habitual, explora a história dessa intervenção, e discute seus resultados e mecanismos das complicações do procedimento, imediatas e tardias, entre eles a rara, mas temível, erosão cardíaca.

Complementam a edição outros artigos originais de muito interesse, com temas como a influência da pré-dilatação nas ICP de pacientes com síndrome coronária aguda sem supradesnivelamento do segmento ST, a ocorrência e o impacto prognóstico da insuficiência renal aguda na evolução hospitalar dos pacientes com infarto do miocárdio com supradesnivelamento do segmento ST tratados percutaneamente, os preditores de eventos 
adversos cardíacos maiores em uma grande série de diabéticos tratados ou não com stents farmacológicos, os desconfortos do procedimento e custos das ICPs por via radial e femoral, e a utilização de modelos experimentais para a avaliação e desenvolvimento de diferentes dispositivos coronários baseados em cateter.

Por último, fizemos um levantamento dos artigos de mais procura das quatro últimas edições da $\mathrm{RBCl}$ até $1^{\circ}$ de dezembro de 2013 em nosso website (Tabela). Essa análise permite avaliar os temas que despertaram maior interesse, ajudando, assim, a redirecionar o curso editorial sempre que necessário.

Finalizando, gostaria de agradecer à diretoria da $\mathrm{SBHCl}$, que ora encerra sua gestão, em especial ao presidente Doutor Marcelo Queiroga, e ao diretor de comunicações, Doutor José Ary Boechat, pela convivência, pela cooperação e pelo apoio fundamentais para a condução da RBCI no biênio 2012-13. Agradeço também pelo trabalho incansável dos membros do Conselho Editorial, revisores e autores, peças fundamentais para a construção de uma revista cada vez mais sólida e reconhecida no cenário científico; pela dedicação e pelo profissionalismo do pessoal técnico relacionado à produção do nosso periódico; e pelo interesse dos nossos leitores - razão primordial da existência desta publicação.

Um excelente 2014 para todos vocês!

Áurea J. Chaves

Editora

TABELA

Artigos da RBCI de mais procura publicados no último ano

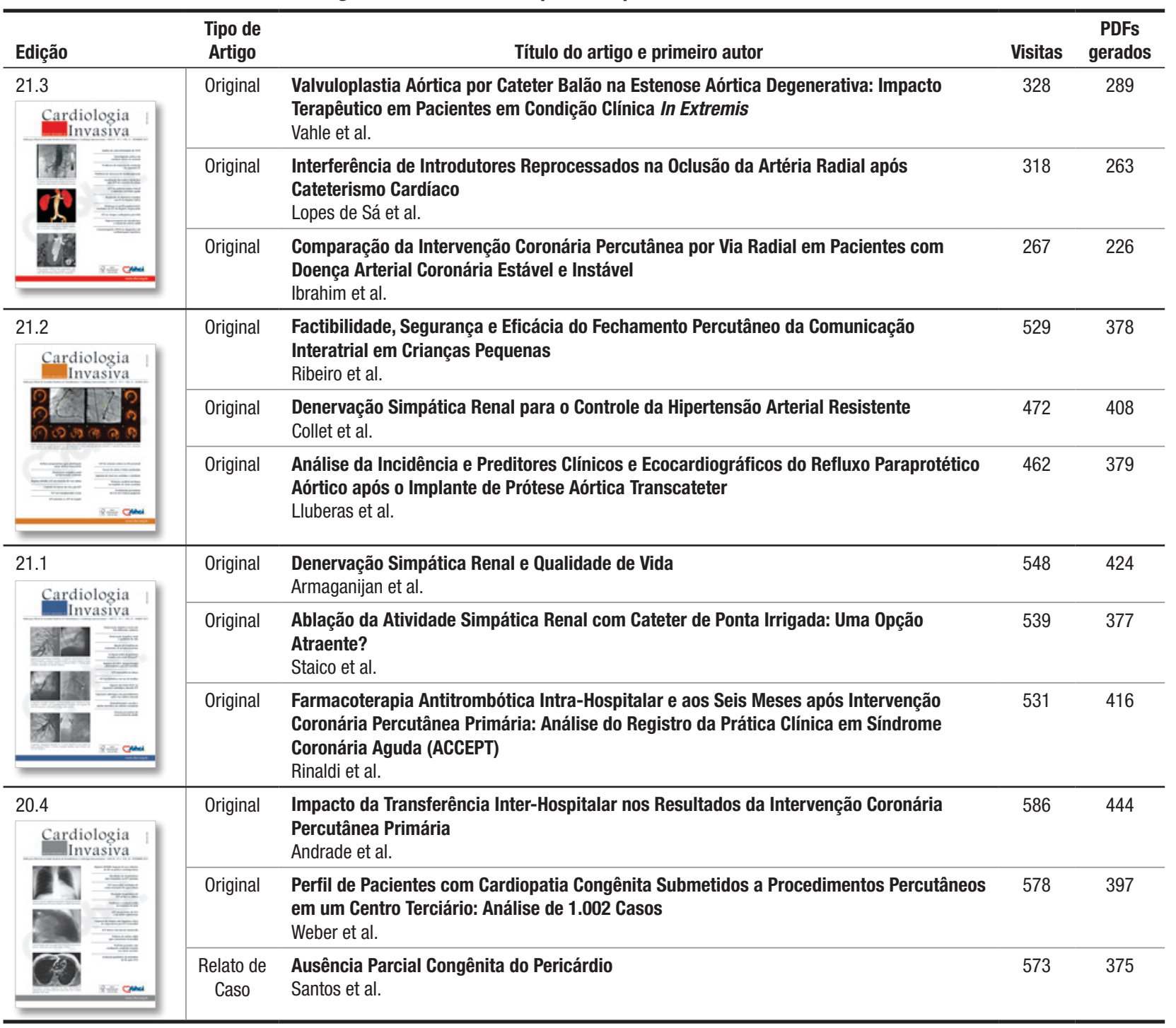

